\title{
CUANDO LA TECNOLOGÍA DEJA DE SER UNA AYUDA DIDÁCTICA PARA CONVERTIRSE EN MEDIACIÓN CULTURAL.
}

Resumen: Las mediaciones tecnocomunicativas que experimentan los jóvenes a través de los nuevos artefactos tecnológicos, les permiten establecer novedosas relaciones con la lectura y la escritura y, en consecuencia, con el conocimiento. Estas formas chocan con las que ha venido fomentando la escuela moderna, y ahora son cuestionadas por los adolescentes más proclives a las que propicia la cultura digital hegemónica.

Palabras clave: Mediaciones tecnológicas, identidades, cultura, educación, conocimiento, racionalidad técnica.

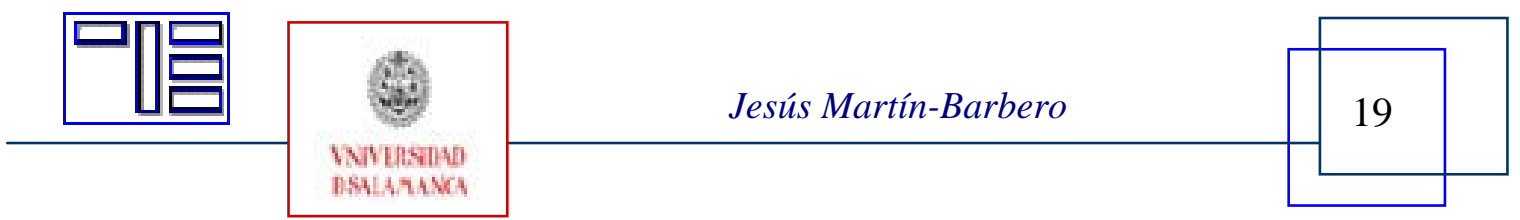




\title{
WHEN THE TECHNOLOGY STOPS BEING A DIDACTIC AID TO BECOME CULTURAL MEDIATION.
}

\begin{abstract}
The technocommunicatives mediations that young people experience through of new technological devices, allow them to establish original relationship with reading and writing and, in consequence, with the knowledge. These forms hit with the ones that the modern school has being fomenting, and now are questioned by the most inclined adolescents to those ones provided by hegemonic digital culture.
\end{abstract}

Keywords: Technological mediations, identities, culture, education, knowledge, technical rationality.

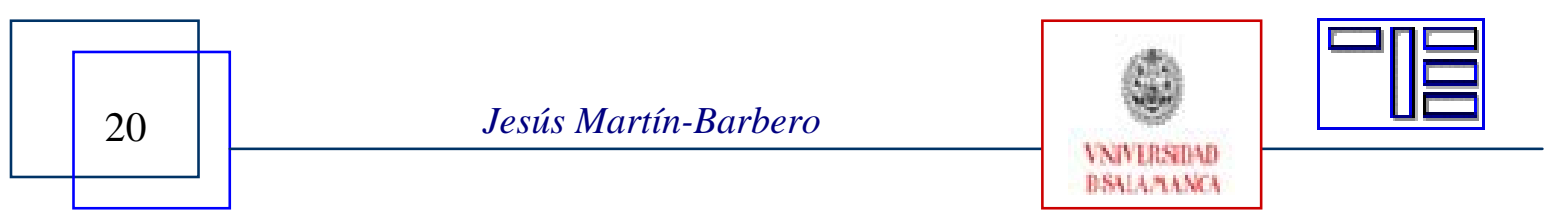




\section{QUAND LA TECHNOLOGIE CESSERA D'ÊTRE UNE AIDE DIDACTIQUE POUR SE TRANSFORMER EN MÉDIATION CULTURELLE.}

Sommaire: Les médiations tecnocomunicativas qu'éprouvent les jeunes à travers nouveaux artefacts technologiques, leur permettent d'établir des relations nouvelles avec la lecture et l'écriture et, en conséquence, avec la connaissance. Ces manières heurtent avec lesquelles il a favorisé l'école moderne, et maintenant elles sont interrogées par les adolescents les plus enclins à celles qui rend propice la culture numérique hégémonique.

Mots clefs: Médiations technologiques, identités, culture, éducation, connaissance, rationalité technique.

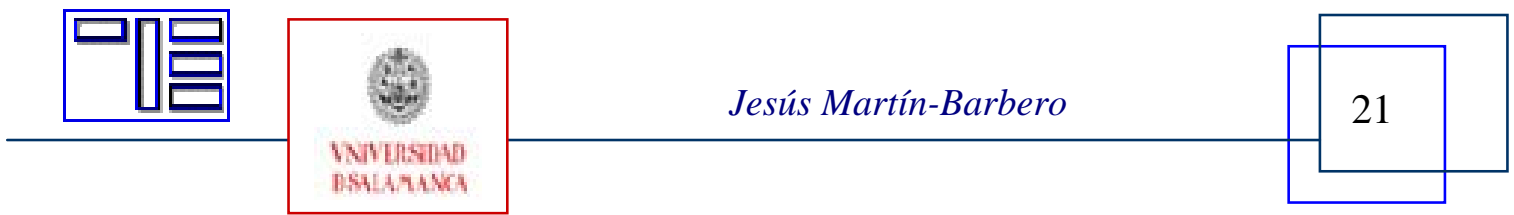




\section{CUANDO LA TECNOLOGÍA DEJA DE SER UNA AYUDA DIDÁCTICA PARA CONVERTIRSE EN MEDIACIÓN CULTURAL.}

Jesús Martín-Barbero

jemartin@cable.net.co

Universidad Javeriana de Bogotá.

Comencemos por una paradoja: la técnica -que fue durante siglos considerada como mero instrumento o utensilio, es decir, algo desprovisto de la menor densidad cognitivave ahora transformado su estatus radicalmente, pasando a constituirse en dimensión estructural de las sociedades contemporáneas a la vez que se llena de densidad simbólica y cultural. Y mientras eso sucede, la política está viviendo un proceso inverso: el que fue uno de los ámbitos más llenos de densidad simbólica, pues configuraba el modo de construir ciudadanía y de tejer el lazo social, se ha transformado en los últimos treinta años en un saber-hacer predominantemente técnico, es decir, en un saber instrumental del que desaparece la densidad ideológica y simbólica, es decir su capacidad de convocar, y de hacer sentirse junta a la gente.

En la institución escolar, en el modelo escolar de educación, asistimos a un proceso parecido: lo que fue un ámbito de socialización densa se ha ido convirtiendo en un ámbito cada vez más dedicado a la administración de saberes, que los expertos ahora denominan competencias, como si con esa palabra mágica se pudieran conjurar todos los conflictos que aquejan a la educación, cuando lo que en verdad están logrando es estandarizar su calidad y “abaratarla” de-socializándola, esto es, sometiéndola a los parámetros provenientes de la reingeniería empresarial y la competitividad del mercado.

La tecnología es percibida entonces entre los críticos de aquélla como destructora de la hegemonía que la escuela compartía sólo con la familia, la de ser la base de la socialización y la transmisión de saberes. Pues bien, mientras tanto la escuela como la familia atraviesan la misma crisis que erosiona a las grandes instituciones de la modernidad, son los medios de comunicación y las tecnologías de la información -del cine y la radio a la televisión, los cómics, la videomúsica, los videojuegos e internet- los que están socializando a los adolescentes, ya que son esos medios los que actualmente les proporcionan modelos y pautas de comportamiento, incluidos los ritos de iniciación que, si tienen mucho de trampa y de frivolidad tienen también mucho de empatía con una nue-

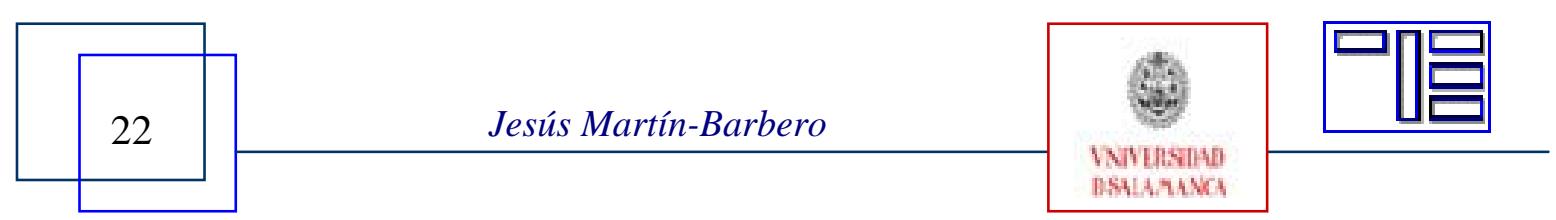


va sensibilidad de la que ni la familia ni la escuela parecen querer entender, incapaces de descifrarla y mucho menos hacerse cargo de ella. Así, mientras la escuela trata de "ponerse al día” o de "modernizarse” llenándose de aparatitos tecnológicos que no sabe usar sino como "ayudas didácticas" que amenicen el sopor y las inercias de la jornada escolar, aquélla proyecta sobre los medios y las tecnologías que configuran hoy un verdadero ecosistema comunicativo de la sociedad, una mirada despectiva y moralista culpándolos de estar corrompiendo a la juventud.

Aunque aún en nuestros países no esta pasando ya algo que sucede actualmente en Estados Unidos y especialmente en Europa, debería al menos alertarnos sobre la hondura de la brecha que separa al sistema educativo de la experiencia de los jóvenes. Me refiero a la agresiva rebelión de los adolescentes contra sus maestros constituyéndose en uno de los problemas más serios de las escuelas secundarias de Alemania, Francia, Inglaterra o España. El simulacro aquel del cual habló hace muchos años Bourdieu -la escuela lugar donde los maestros hacen como que enseñan a alumnos que hacen como que aprenden pero donde todo funciona- ha comenzado a estallar estruendosamente. Y no por causa de los maestros o de los alumnos sino de un modelo de comunicación escolar que nada tiene que ver con las dinámicas comunicativas de la sociedad, es decir por causa de una escuela que sigue exigiendo a los alumnos dejar fuera de ella su cuerpo y su alma, sus sensibilidades, sus experiencias y sus culturas, sean éstas sonoras, visuales, musicales, narrativas o escriturales.

Todo lo cual nos está exigiendo pensar seriamente los desafíos que la tecnología le plantea hoy al sistema escolar, y cómo podría el sistema escolar asumir esos desafíos, no en forma suicida como lo ha hecho hasta ahora, sino dejándose interpelar, cuestionar y refundar porque a través de la tecnología quien desafía a la escuela es la propia sociedad.

\section{1.- MEDIACIONES TECNOCOMUNICATIVAS DE LA CULTURA.}

El pensamiento actual acerca de las relaciones entre cultura y tecnología llega mayoritariamente a conclusiones desesperanzadas y se detiene. Los conservadores culturales dicen que la televisión por cable es la última ofrenda de la caja de Pandora y la transmisión por satélite coronará la torre de Babel. Al mismo tiempo una nueva clase de intelectuales, que dirige los centros en que operan las nuevas tecnologías culturales e informáticas, hablan confiadamente de su 'producto'. Ninguna de esas posturas es un suelo firme. Lo que tenemos es una pésima combinación de determinismo tecnológico y pesimismo cultural. Así, conforme una tras otra de las viejas y elegantes instituciones se ven invadidas por los imperativos de una más dura economía capitalista no resulta sorprendente que la única reacción sea un pesimismo perplejo y ultrajado. Porque no hay nada que la mayoría de esas instituciones quiera ganar o defender más que el pasado, y el futuro alternativo traería precisa y obviamente la pérdida final de sus privilegios.

Raymond Williams

Dos procesos están transformando radicalmente el lugar de la cultura en nuestras sociedades: la revitalización de las identidades y la revolución de las tecnicidades. Los procesos de globalización están reavivando la cuestión de las identidades culturales -

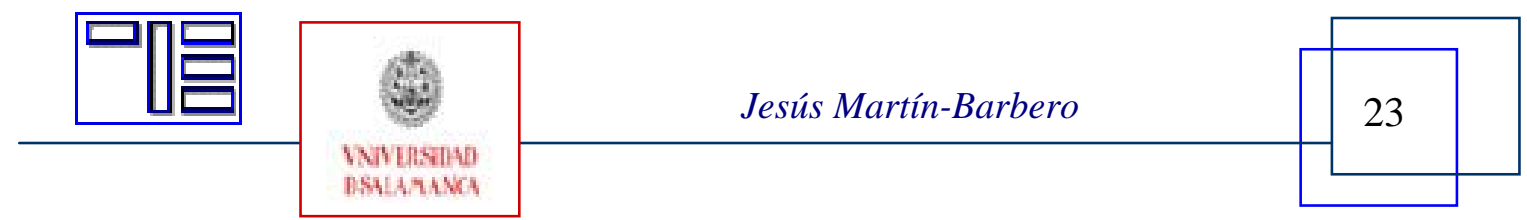


étnicas, raciales, locales, regionales- hasta el punto de convertirlas en dimensión protagónica de muchos de los más violentos y complejos conflictos internacionales de los últimos años, al mismo tiempo que las identidades, incluidas las de género y de edad, están reconfigurando la fuerza y el sentido de los lazos sociales, y las posibilidades de convivencia en lo nacional y en lo local. De otra parte, atravesamos una revolución tecnológica cuya peculiaridad no reside tanto en introducir en nuestras sociedades una cantidad inusitada de nuevas máquinas sino en configurar un nuevo modo de relación entre los procesos simbólicos -que constituyen lo cultural- y las formas de producción y distribución de los bienes y servicios: un nuevo modo de producir, asociado a un nuevo modo de comunicar, convierte a la información y al conocimiento en fuerza productiva directa (Castells).

El lugar de la cultura en la sociedad cambia cuando la mediación tecnológica de la comunicación deja de ser meramente instrumental para espesarse, densificarse y convertirse en estructural. De ahí que la tecnología remita hoy tanto o más que a unos aparatos a nuevos modos de percepción y de lenguaje, a nuevas sensibilidades y escrituras. La pregunta por la técnica se nos vuelve entonces cada día más crucial en la medida en que la diversidad cultural de la técnica, persistentemente testimoniada por los antropólogos, es aceleradamente sustituida por la existencia de una tecnicidad-mundo que desvincula a la tecnología de las herencias culturales permitiéndole instalarse en cualquier región o país como dispositivo de producción a escala planetaria: como conector universal en lo global. Al mismo tiempo, al profundizar la división internacional del trabajo la tecnicidad-mundo trastorna las condiciones de producción rearticulando las relaciones entre países mediante una des-centralización que concentra el poder económico y una des-localización que empuja la hibridación de las culturas.

\subsection{Racionalidad técnica y ecosistema comunicativo.}

Estamos ante un nuevo tipo de técnica cuya peculiaridad reside en constituirse en ingrediente estructural de la formación de un verdadero ecosistema comunicativo. Ecosistema que emerge asociado a una nueva economía cognitiva regida por el desplazamiento del número que, de signo del dominio sobre la naturaleza, está pasando a convertirse en mediador universal del saber y del operar técnico/estético, lo que viene a significar la primacía de lo sensorio/simbólico sobre lo sensorio motriz. La numerización digital hace posible una nueva forma de interacción entre la abstracción y lo sensible, replanteando por completo las fronteras entre arte y ciencia. Si desde antiguo la ciencia ha teorizado modos de percepción prefigurados por el arte, hoy no podemos ya extrañarnos de que el artista trabaje programando música o poesía. Pues por escandaloso que eso suene al oído romántico es sólo un indicador de la hondura del cambio que convierte a la simulación informática a la vez en ámbito de experimentación científica y de creación estética. El significado mayor de ese cambio remite al sentido emancipador que cobra el hacer técnico en su estrecha vinculación con la experiencia estética. Esto es, un arte cada día más sometido, o vuelto cómplice, de las presiones del mercado, que asimila la temporalidad de las obras a la obsolescencia de cualquier producto comercial,

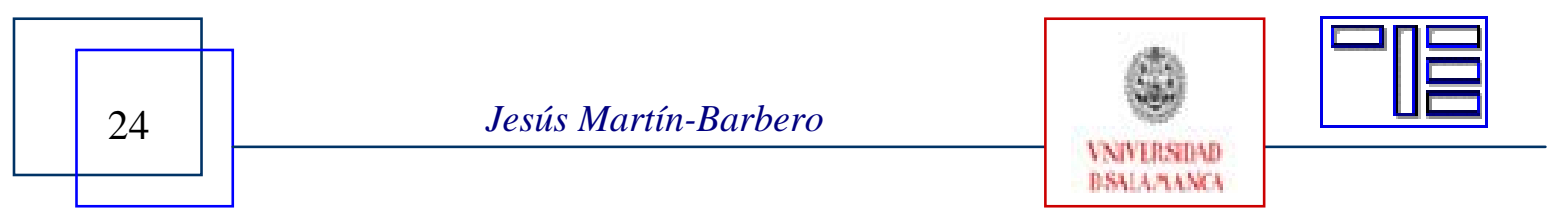


encuentra en la nueva tecnicidad posibilidades de revertir el creciente déficit simbólico que padece. $\mathrm{Y}$ a su vez, en la experimentación tecnológica la creación artística hace emerger un nuevo parámetro de evaluación de la técnica, distinto al de su rentabilidad o su funcionalidad de control, el de su capacidad de significar, esto es de auscultar y descifrar las más secretas energías que irrigan y dinamizan el opaco y contradictorio curso del vivir social.

La mirada crítica nos advierte certeramente de los riesgos que entraña el actual desarrollo tecnológico en sus complicidades con las lógicas del mercado y los procesos de agravamiento de la exclusión social. A donde apunta la pregunta por ¿cómo asumir el espesor social y perceptivo que hoy revisten las tecnologías comunicacionales, sus modos transversales de presencia en la cotidianidad desde el trabajo al juego, sus espesas formas de mediación tanto del conocimiento como de la política?; ¿cómo resistir al realismo de lo inevitable que produce la fascinación tecnológica?; ¿cómo no dejarse atrapar en la complicidad discursiva de la modernización neoliberal con el saber tecno-lógico según el cual la historia habría encontrado su fin en los avatares de la información y la comunicación? Es por ello que nuestra inserción en la nueva mundanidad técnica no puede ser pensada como un automatismo de adaptación socialmente inevitable sino más bien como un proceso densamente cargado de ambigüedades, de avances y retrocesos, un complejo conjunto de filtros y membranas (Mancini) que regulan selectivamente la multiplicidad de interacciones entre los viejos y los nuevos modos de habitar el mundo.

De otra parte, no es cierto que la penetración y expansión de la innovación tecnológica en el entorno cotidiano implique la sumisión automática a las exigencias de la racionalidad tecnológica, de sus ritmos y sus lenguajes. De hecho lo que está sucediendo es que la propia presión tecnológica está suscitando la necesidad de encontrar y desarrollar otras racionalidades, otros ritmos de vida y de relaciones tanto con los objetos como con las otras personas, relaciones en las que la densidad física y el espesor sensorial son el valor primordial. De eso hablan la obsesión por la gimnasia y los deportes, o la búsqueda de las medicinas alternativas o de "terapias de relaciones", en su esfuerzo por reencontrarse con el propio cuerpo recobrando el contacto y la inmediatez en la comunicación. Cierto, la mediación tecnológica se espesa cada día más trastornando nuestra relación con el mundo, pero ese cambio no remite sólo a la técnica, él hace parte del proceso mucho más ancho y hondo de racionalización del mundo que, según M. Weber, constituye el núcleo más duro y secreto del movimiento de la modernidad.

\subsection{Producción de conocimiento: otras figuras de razón.}

Un segundo plano de cambios, menos visibles socialmente, es aquel en que se sitúan las transformaciones de los propios modos de producción del conocimiento. Se trata, en últimas, de la aparición de nuevas figuras de razón (G. Chartron) que replantean algunos de los rasgos más paradigmáticos del proceso de elaboración de la ciencia, como las que afectan a la idea de certeza (I. Prigonine) y de experiencia (B. de Sousa Santos). No

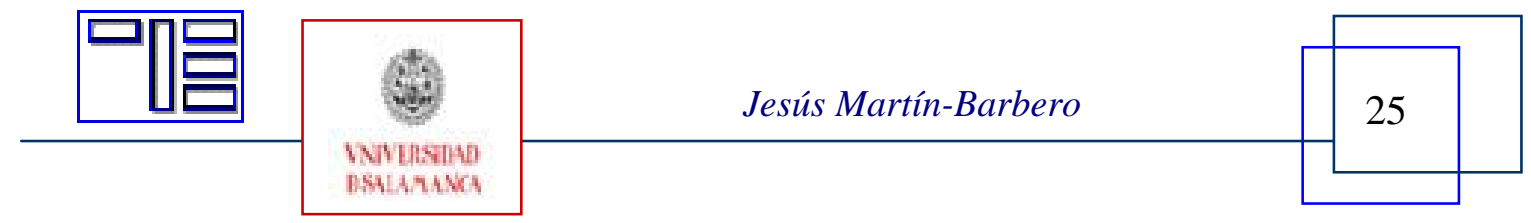


hay una sola racionalidad desde la que sean pensables todas las dimensiones de la actual mutación civilizatoria. Y uno de lo más claros avances apunta hoy a la creciente conciencia de la complejidad incluyendo la disonancia cognitiva que implica hablar, como lo hace el mismo E. Morin, de la pluralidad de inteligencias que entran en juego cuando hoy hablamos de conocimiento.

De otra parte los nuevos saberes remiten a nuevas figuras de razón que nos interpelan desde la tecnología. Con el computador estamos no ante una máquina más con la que se producen objetos sino ante un nuevo tipo de tecnicidad que posibilita el procesamiento de informaciones y cuya materia prima son abstracciones y símbolos. Lo que inaugura una nueva aleación de cerebro e información que sustituye a la tradicional relación del cuerpo con la máquina. De otro lado, las redes informáticas al transformar nuestra relación con el espacio movilizan figuras de un saber que escapa a la razón dualista con la que estamos habituados a pensar la técnica (F. Broncano), pues se trata de movimientos que son a la vez de integración y de exclusión, de desterritorialización y relocalización, nicho en el que interactúan y se entremezclan lógicas y temporalidades tan diversas como las que entrelazan en el hipertexto a las sonoridades del relato oral con las intertextualidades de la escritura y las intermedialidades del audiovisual. Una de las más claras señales de la hondura del cambio en las relaciones entre cultura, tecnología y comunicación, se halla en la reintegración cultural de la dimensión separada y minusvalorada por la racionalidad dominante en Occidente desde la invención de la escritura y el discurso lógico, esto es la del mundo de los sonidos y las imágenes relegado al ámbito de las emociones y las expresiones. Al trabajar interactivamente con sonidos, imágenes y textos escritos, el hipertexto hibrida la densidad simbólica con la abstracción numérica haciendo reencontrarse las dos, hasta ahora "opuestas", partes del cerebro. De ahí que de mediador universal del saber, el número esté pasando a ser mediación técnica del hacer estético, lo que a su vez revela el paso de la primacía sensoriomotriz a la sensorio simbólica.

\section{2.- OTRA CULTURA PARA UNA ESCUELA NUEVA.}

La segunda parte de mi reflexión, tiene que ver con la manera como la escuela resiente la presencia de la nueva tecnicidad. Y me refiero específicamente a dos procesos de cambio: el primero -el más extendido pero el menos pensado por la escuela- es el proceso de descentramiento y diseminación de los saberes por fuera de la institución escolar. Soy un convencido de que si históricamente el saber ha estado siempre ligado al poder, si los sabios han habitado históricamente un palacete cercano al de los soberanos, los cambios en los modos de circulación de los saberes desvelan una de las dimensiones decisivas en la transformación de las figuras y del ejercicio del poder. Y es lo que estamos empezando a vivir en los últimos años, aunque obviamente ya se hayan puesto en marcha también todos los modos posibles de control de esa apenas iniciada etapa de hegemonía de la libertad sobre la propiedad, incluida la tramposa propiedad que se reviste -o mejor se trasviste- detrás el digno apellido de intelectual (P. Lévy). Pero lo que aun no se ha podido impedir es que montones de saberes socialmente valiosos circulen

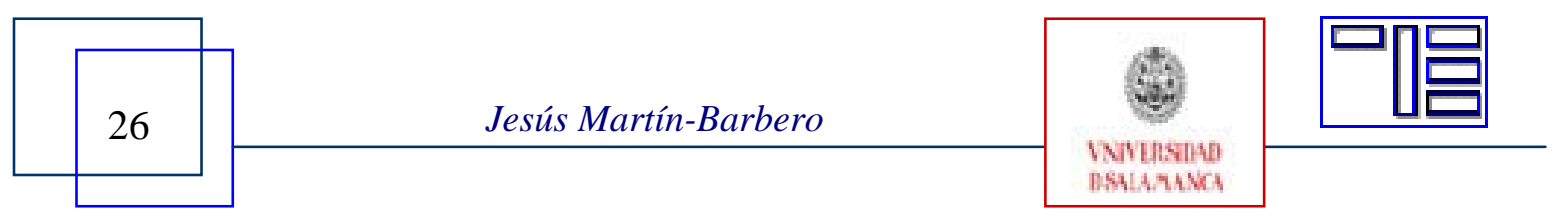


por fuera de la escuela, y sin pedirle permiso a la institución escolar circulan por la radio, la televisión, el cine, los videojuegos, y última y descaradamente en internet.

Esa des-localización de los saberes, afecta a la escuela en su centro, pues se produce desde lo que hace años Abraham Moles llamó saberes-mosaico, que fue una primera forma de invocar al hipertexto, y de llevar la crisis hasta el corazón mismo del sistema escolar, a su modelo letrado de saber, equiparado con el modelo de escritura y lectura del libro: la secuencia lineal de izquierda a derecha y la verticalidad del arriba hacia abajo. Que es reduplicada por la normalización de la secuencia de grados y edades como modo secreto de control de los alumnos. Y pobre del chico o chica que no sea normal, es decir no quepa exactamente y del todo en un solo grado, o estás en cuarto o estás en quinto, lo que no se puede es estar entre, que es en lo que están muchos alumnos hoy. Pues los adolescentes llegan hoy a la escuela con un montón de saberes, incluidos saberes matemáticos, históricos, estéticos, que no tienen la forma del saber lineal, secuencial y vertical (M. Mead) con el que ha identificado su forma y su función la escuela y desde el que se arroga ser el único órgano legítimo de transmisión de los saberes.

El desconcierto de los maestros ante el tipo de preguntas que les hacen los adolescentes o ante el tipo de silencios y de aburrimientos de los alumnos, se expresa mayoritariamente -hay preciosas experiencias excepcionales- tapando con autoritarismo más de lo mismo. Pero que nadie me malentienda: no estoy echando la culpa a los maestros, lo que estoy haciendo es confrontar el sistema escolar con el nuevo sistema comunicativo de la sociedad. Sé muy bien cuales son las condiciones de trabajo de la mayoría nuestros maestros, especialmente en nuestras escuelas públicas e incluso en muchas escuelas privadas, pero no estoy hablando de las condiciones de trabajo -que indudablemente influyen en cómo se realiza la práctica pedagógica- ni estoy olvidando los esfuerzos cotidianos con que los maestros tratan de asumir los desafíos de los que estamos hablando.

Y para que esto quede claro, un ejemplo. Un amigo psicólogo que hacía su tesis hace un año en ciudad Bolívar, la enorme subciudad repleta de desplazados por la guerra que vive Colombia, venidos del país entero y muchos de la Costa atlántica y Caribe, observó cómo en una escuela al mimo tiempo en que los maestros y maestras trataban de educar a los niños y las niñas costeños destruían las bases de su propia cultura. Pues resulta que el vocabulario de los costeños no tiene nada que ver con el vocabulario de los nativos de Bogotá y mucho menos con el de los libros que se leen en las escuelas de Bogotá. Con el agravante de que la riqueza de ese vocabulario está profundamente ligada a una enorme y anárquica creatividad gestual y narrativa. Confundiendo hablar distinto con hablar mal, los maestros se propusieron enseñar a los niños costeños a hablar bien. ¿Con qué resultado? ¡Un año y medio después mi amigo psicólogo se encontró con que los niños de esa escuela se habían vuelto mudos! Porque ahora sólo hablaban cuando estaban seguros de saber decir las cosas con las palabras que estaban en los libros. Es lo mismo que pretendieron hacer con los colombianos, en general, los gramáticos en el siglo XIX al exigir que para ser ciudadanos plenos había que tener "propiedad

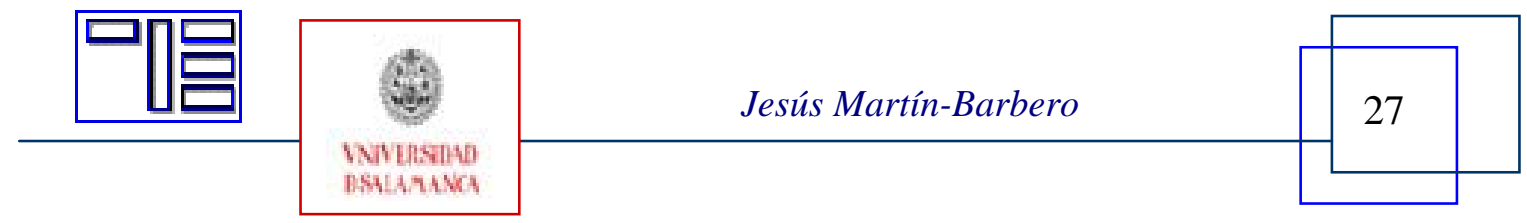


Revista Electrónica Teoría de la Educación.

Educación y Cultura en la Sociedad de la Información.

http://www.usal.es/teoriaeducacion

Vol. 10. No1. Marzo 2009

en el hablar” y eso sólo se adquiría hablando como se escribe. Esto es, confundiendo la cultura oral con analfabetismo e in-cultura en nombre de una cultura letrada que, en lugar de venir a enriquecer su cultura oral, les dejaba mudos. Al despreciar su cultura oral lo que se destruye no afecta sólo al lenguaje sino a la creatividad narrativa, es decir a su más densa identidad.

Lo que no cabe en la escuela son los nuevos modos de leer y de escribir, que no quieren aceptar ni las Facultades, ni los Ministerios de educación. Pues se sigue creyendo que lo único que se leen son libros aunque hoy los adolescentes lean muchas cómics, videojuegos y rock que son sus nuevas formas de escribir. Pero nuestro anacrónico sistema escolar que cree que la solución es meter la escuela en la televisión en lugar de meter la televisión en la escuela para que los alumnos aprendan a leer las trampas de los noticieros de televisión, la mediocridad de las telenovelas, la estupidez de montones de magazines y sepan apreciar lo poco que haya de valioso en la televisión.

Estamos, pues, ante un segundo proceso de cambio mucho más radical aún. Me refiero a los nuevos modos de producción de conocimiento, y más específicamente a la, ya apuntada, nueva relación entre lo sensible y lo inteligible. Ahí está la lucidez de Castells ligando la mutación digital a la superación definitiva de la separación entre los dos lóbulos del cerebro: el de la razón argumental y el de la emoción pasional; ¡que no por mera casualidad resulta ser el del arte! Pues hoy lo que en ciencias como la física y la biología se llama cada día más frecuentemente experimentar es simular digitalmente en computador. O sea que en lugar de coger a un ratoncito entero y someterle a un despiece en vivo se puede simular su hígado digitalmente en figuras e imágenes de computador, y observar cómo funciona en diversas condiciones hasta llegar a hacer un diagnóstico con mayor precisión que trabajando directamente sobre el riñón del ratoncito. Y así asistimos a un cambio radical en el estatuto cognitivo de la imagen que, de sinónimo de apariencia o engaño, está entrando, vía numerización/digitalización, a formar parte del proceso de construcción del conocimiento.

Para terminar sintetizo el resultado de una investigación que hice durante año y medio en Guadalajara (México), sobre los usos adolescentes de internet. Lo hicimos con 25 alumnos que finalizaban la carrera de comunicación y con tres monitores, alumnos míos de maestría. Investigamos los usos del computador en la casa, en la escuela y en el cibercafé. Y ¿qué descubrimos? Pues que el lugar donde el uso del computador era más explorador e inventivo era en los cibercafés, y era más inerte y pasivo en la escuela. $\mathrm{Y}$ nos encontramos incluso con algo que avergüenza el nacionalismo mexicano: a usar el computador se enseña en las escuelas públicas con un manual de Microsoft, iy al final del aprendizaje les dan a los alumnos un cartón firmado por Bill Gates! Todo lo que en el computador hay de interfaz entre el trabajo y el juego -que es la clave de la creatividad en esa etapa de la vida- es prohibido, y de esta manera lo que la escuela les enseña no es a jugar/disfrutar del computador, sino tareas prediseñadas que castran de raíz las potencialidades de búsqueda arriesgada y de escrituras diversas, en últimas las posibilidades de buscar y perderse, sin las cuales es imposible el interactuar, el descubrir y el

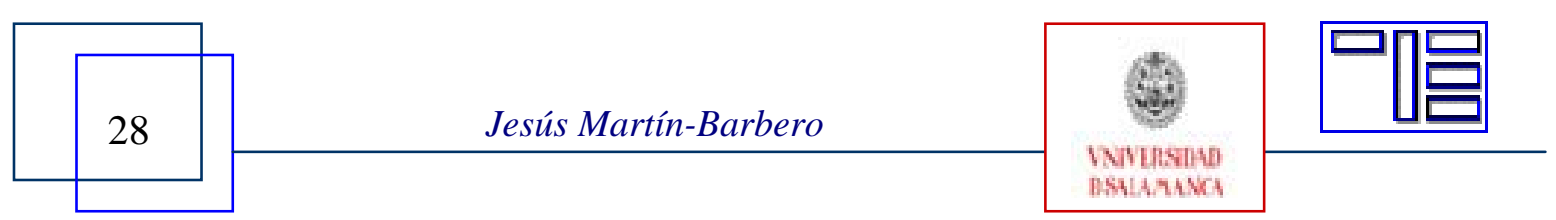


innovar. Puesto que el juego es únicamente para la hora del recreo, la escuela resulta incapaz de entender el más antiguo y el más nuevo sentido que tiene el verbo navegar, que es a la vez conducir y explorar, manejar y arriesgar.

Es en la trama de interacciones entre sujetos donde hoy las mediaciones tecnológicas revelan su potencial alternativo por más que para los apocalípticos esas mediaciones signifiquen todo lo contrario: la tendencia de los adolescentes al ensimismamiento, el computador volviéndolos agarofóbicos, dominándolos como una adicción que los aísla y desvincula de la realidad. No es que no haya algo de cierto hoy en esos temores, pero lo que revelan las investigaciones sobre los usos que los jóvenes hacen del computador muestran otro panorama. Como nos mostró la investigación antes citada, en la que ni la adicción, ni el aislamiento, ni la pérdida del sentido de la realidad son la tendencia más visible. En nuestros países la gente joven que usa frecuentemente internet sigue igualmente frecuentando la calle, gozando la fiesta de fin de semana y prefiriendo la compañía al aislamiento. Hay una cierta adicción, pero esa ni es la única ni la más fuerte, y desde luego no es esa de la que se muere sino de otras bien distintas. Un ejemplo entre otros de la sociabilidad no perdida: muchachos que tienen computador en casa y sin embargo van al cibercafé a jugar porque es allí donde pueden compartir los hallazgos de la navegación y las aventuras del juego con los amigos presentes.

Todo lo cual nos implica replantear el tema de las humanidades radicalmente, como, en Normas para el parque humano, lo ha hecho Peter Sloterdijk, atreviéndose a afirmar que las humanidades en Occidente han sido en gran medida el instrumento con el cual se ha logrado amansar la innata ferocidad humana al mismo tiempo que se castraba su capacidad para rebelarse. Y Savater tomó partido en la polémica enorme que se armó en Europa alrededor de este panfleto planteando esta pregunta: ¿qué es lo que en últimas pone en juego la educación hoy: el modelo humanista que se conserva en el gabinete del bibliófilo contra el estruendo y la furia del espectáculo audiovisual, o la reinvención de lo humano, de su sociabilidad? Pues si el modelo humanista está sirviendo para distanciarnos de los miedos, las angustias y los sueños de la mayoría de los humanos, Savater concluye así de contundente: "ni los libros por buenos que sean, ni las películas ni toda la telepatía mecánica sino el semejante que se ofrece cuerpo a cuerpo a la devoradora curiosidad juvenil, esa es la educación humanista, la que desentraña críticamente en cada mediación escolar, sea libro, filmación o cualquier otra herramienta comunicativa, lo bueno que hay en lo malo y lo malo que se oculta en lo más excelso, porque el humanismo no se lee ni se aprende de memoria, sino que se contagia, y sea como fuere los libros ni tienen la culpa ni son la solución”.

\section{3.- REFERENCIAS.}

BERK, E. and DEVLIN, J. [eds.] (1991): Hypertext/Hypermedia Handbook. New York, Intertext Publications.

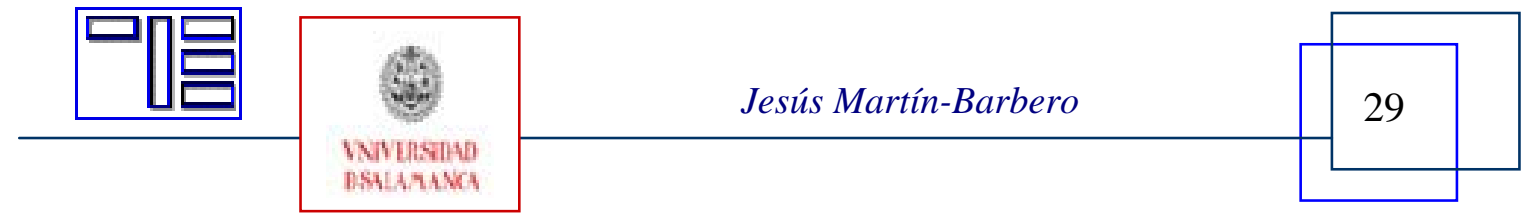


CASATELLS, M. (1998): La era de la información, Vol.1. Madrid, Alianza.

-- (2002): La dimensión cultural de internet.En Cultura y sociedad del conocimiento: presente y perpectivas de futuro. Barcelona, UOC.

CHARTIER, R. (2001): Lecteurs et lectures a l'age de la textualité electronique. Paris. Centre Pompidou.

CHARTRON, G. (1994): Pour une nouvelle economie du savoir. Rennes, Presses Universitaires de Rennes.

DELANY, P. and LANDOW, G. [eds.] (1991): Hypermedia and Literary Studies Cambridge. Cambridge-Massachusetts, MIT Press.

DE SOUSA SANTOS, B. (2000): Crítica da razao indolente. Contra o despedício da experiencia. São Paulo, Cortez.

ECHEVERRÍA, J. (1994): Telépolis. Barcelona, Destino.

-- (1999): Los señores de aire y el Tercer Entorno. Barcelona, Destino.

LEVIN, M. [ed.] (1993): Modernity and hegemony of vision. Berkeley, Univ. of California.

LÉVY, P. (1994): L'intelligence colective. Pour une antropologie du cyberespace. Paris, La Decouverte.

-- (1996): O que é o Virtual? São Paulo, Ed. 34.

-- (2003): El anillo de oro y la propiedad intelectual, Rev. Multitudes, 5.

MANZINI, E. (1991): Artefacts. Vers une nouvelle écologie de l'environement artificiel. Paris, CGP.

MEAD, M. (1971): Cultura y compromiso. Buenos Aires, Granica.

MARTÍN-BARBERO, J. y REY, G. (1999): Los ejercicios del ver. Barcelona, Gedisa.

-- (2003): Usos adolescentes de Internet. Cibernautas y cibercreadores. Guadalajara (México), Departamento de Estudios Socioculturales del ITESO.

SAVATER, F. (2001): Opinión. El país, 5 de abril, Madrid.

SLOTERDIJK, P. (2001): Normas para el parque humano. Madrid, Taurus.

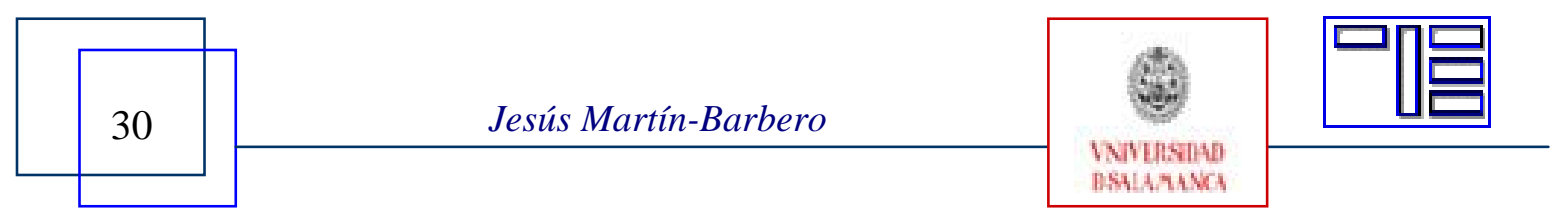




\begin{tabular}{|c|c|c|}
\hline ص包 & $\begin{array}{l}\text { Revista Electrónic } \\
\text { Educación y Cultura en }\end{array}$ & $\begin{array}{l}\text { ducación. } \\
\text { la Información. }\end{array}$ \\
\hline & http://www.usal.es/teoriaeducacion & Vol. 10. Nº 1. Marzo 2009 \\
\hline
\end{tabular}

Para citar el presente artículo puede utilizar la siguiente referencia:

MARTÍN-BARBERO, Jesús (2009). Cuando la tecnología deja de ser una ayuda didáctica para convertirse en mediaci. En SAN MARTÍN ALONSO, A. (Coord.) Convergencia Tecnológica: la producción de pedagogía high tech [monográfico en línea]. Revista Electrónica Teoría de la Educación: Educación y Cultura en la Sociedad de la Información. Vol. 10, $\mathrm{n}^{\circ}$ 1. Universidad de Salamanca [Fecha de consulta: $\mathrm{dd} / \mathrm{mm} /$ aaaa].

http://www.usal.es/ teoriaeducacion/rev_numero_10_01/n10_01_martin-barbero.pdf ISSN: 1138-9737

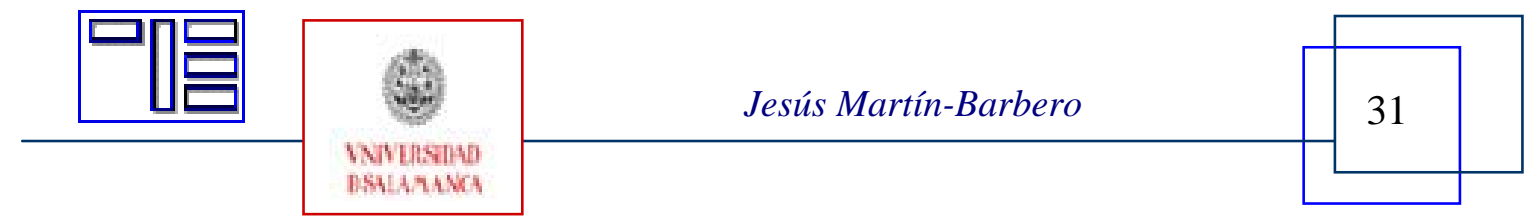

